\title{
ASPECTOS EPIDEMIOLÓGICOS E INFLUÊNCIA DE VARIÁVEIS CLIMÁTICAS NOS CASOS NOTIFICADOS DE MENINGITE EM CRIANÇAS NO MUNICIPIO DE PONTA GROSSA - PR, 2002-2011.
}

\author{
POBB, Ketleyn \\ Bióloga - Universidade Estadual de Ponta Grossa - UEPG, Paraná
}

LEITE, Maysa Lima

Professora associada, Departamento de Matemática e Estatística da Universidade Estadual de Ponta Grossa - UEPG, Paraná

VIRGENS FILHO, Jorim Sousa

Professor associado, Departamento de Matemática e Estatística da Universidade Estadual de Ponta Grossa - UEPG, Paraná

STOCCO, Caroliny

Bacharel em Enfermagem, Vigilância Epidemológica e Controle de Doenças da Secretaria Municipal de Saúde de Ponta Grossa, Paraná.

DAL GOBBO, Bruna Luisa

Biológa - Universidade Estadual de Ponta Grossa, Paraná

\begin{abstract}
RESUMO
Os elementos climáticos têm destacada influência sobre a manifestação de muitas doenças nos seres humanos, atuando na manutenção de alguns agentes patogênicos. Além disso, existem doenças que são predominantes em certas zonas climáticas, e outras que apresentam padrão sazonal de incidência como é o caso da meningite. Assim, 0 objetivo deste estudo foi descrever o perfil epidemiológico e avaliar a influência de variáveis climáticas locais sobre a incidência mensal de meningite em crianças de 0 a 9 anos no Município de Ponta Grossa, Paraná, no período de 2002 a 2011. A amostra foi composta de 411 casos notificados e confirmados de crianças residentes nesse município. Uma análise de regressão linear simples foi aplicada com a finalidade de se determinar o maior nível com o qual os elementos climatológicos, avaliados separadamente, foram capazes de evidenciar a relação entre o clima e a incidência da patologia. Os maiores coeficientes de meningite foram encontrados nos meses de Outubro e Novembro, enquanto os menores coeficientes estiveram presente nos meses de Abril e Maio. A etiologia asséptica foi encontrada nos meses mais quentes e com elevado total de precipitação pluviométrica. Nos meses mais frios e com a precipitação pluviométrica mais baixa, a frequência da etiologia bacteriana foi bastante aparente. A análise de regressão linear simples demonstrou alta correlação para a variável precipitação pluviométrica, sugerindo que esta variável climática interfere na incidência da meningite.

PALAVRAS CHAVE: Meningite; Epidemiologia; Variáveis Climáticas.

EPIDEMIOLOGIC ASPECTS AND INFLUENCE OF CLIMATE VARIABLES IN NOTIFIED CASES OF MENINGITIS IN CHILDREN IN PONTA GROSSA-PR, 2002-2011.

ABSTRACT: The climatic elements have highlighted influence on the manifestation of many diseases in humans, working in the maintenance of some pathogens. Furthermore, there are diseases that are prevalent in certain climatic zones, and others that have seasonal pattern of incidence as in the case of meningitis. The objective of this study was to describe the epidemiology and assess the influence of local climatic variables and monthly incidence of meningitis in children 0-9 years old in the city of Ponta Grossa, Paraná, in the period of 2002-2011. The sample consisted of 411 reported and confirmed cases of children living in this city. A simple linear regression analysis was applied for the purpose of determining the highest level to which the climatological elements, evaluated separately, were able to show the relationship between climate and the incidence of the disease. The highest coefficients of meningitis were found in the months October and November while the lowest coefficients were present in the months April and May. Aseptic etiology was found in the warmer months and with a high rainfall. In the cooler and the lowest rainfall months, the frequency of bacterial etiology was quite apparent. A simple linear regression analysis demonstrated a high correlation to the variable rainfall, suggesting that this variable affects climate in the incidence of meningitis.

KEYWORDS: Meningitis; Epidemiology; Climate Variables.
\end{abstract}

\section{INTRODUÇÃO}

A investigação do comportamento epidemiológico de uma doença proporciona informações fundamentais para a redução e a prevenção desse agravo. Assim, quanto maior o

número de variáveis analisadas, mais ampla será a investigação. Dentre essas variáveis, deve-se levar em consideração a epidemiologia da doença e as características climáticas do lugar onde as doenças se manifestam. 
Nesse sentido, o clima sobre uma localidade pode ser compreendido como a síntese de todos os elementos climáticos em uma combinação de certa forma singular, determinada pela interação dos controles e dos processos climáticos, aumentando a incidência de certas doenças que atacam o homem, afetando a resistência do corpo humano a algumas doenças, influenciando o crescimento, a propagação e a difusão de alguns organismos patogênicos ou de seus hospedeiros (OLIVEIRA, 2011).

Tal conhecimento torna-se singular uma vez que os seres humanos estão permanentemente em contato com a atmosfera, e desta forma tornam-se "vítimas" da influência exercida pelo ambiente. O clima e os diferentes tipos de tempo (ondas de calor, períodos de estiagem, variações súbitas das temperaturas) são entendidos como "um fator ambiental capaz de influenciar o organismo humano, não com um caráter determinista, mas como um elemento que pode contribuir de maneira benéfica ou maléfica para a saúde humana" (MURARA e TRINDADE AMORIM, 2010).

Desta forma, o clima atua na manifestação de determinados agravos à saúde, tendo seus elementos- radiação solar, temperatura do ar, umidade, precipitação pluviométrica, pressão atmosférica e ventos - interferência no bem estar dos indivíduos. Esses elementos não são os únicos responsáveis pelo desencadeamento de enfermidades; entretanto, quando vinculados às características físicas, psicológicas e culturais, ou seja, fatores de riscos ligados ao estilo de vida resultam como mais um contribuinte para o agravamento de determinadas enfermidades (MURARA e TRINDADE AMORIM, 2010).

Além disso, algumas doenças tendem a ser predominantes em certas zonas climáticas, enquanto outras, particularmente as infectocontagiosas, tendem a seguir um padrão sazonal em sua incidência. O clima constitui-se numa das dimensões do ambiente urbano e seu estudo tem oferecido importantes contribuições ao equacionamento da questão ambiental e epidemiológica das cidades (OLIVEIRA, 2011). Nesse sentido, pode-se afirmar que a incidência de determinadas doenças está relacionada diretamente com a tropicalidade de algumas regiões do planeta (ARAUJO e NUNES, 2005). É evidente que a variação dos elementos climáticos interfere no aparecimento ou na manutenção de algumas doenças, e por isso a análise da influência do clima na saúde humana é de grande importância.

Sabe-se que vários fatores podem estar associados à expansão dos vetores destas doenças, dentre os quais se destacam as alterações climáticas, mudanças nas paisagens e nos ecossistemas, estabelecimento de novos padrões e modos de vida da população, crescimento e concentração demográfica, debilidade dos serviços de saúde pública, além de aspectos atinentes à própria mutação de vírus e bactérias (MENDONÇA et al., 2009).

Uma doença, considerada sazonal, e grandemente influenciada pelo clima é a meningite, que consiste na inflamação das meninges - membranas que envolvem o cérebro e a medula espinhal, podendo ser causada, principalmente, por vírus ou bactérias. Dentre as infecções do sistema nervoso central, a meningite apresenta as mais altas taxas de morbidade e mortalidade (DAVIS, 2003).

A meningite é um agravo de ocorrência mundial, com manifestações localizadas, além de ser uma doença muito antiga, pois há registros de ocorrências a mais de duzentos anos. Sua expressão epidemiológica depende de fatores como o agente infeccioso, existência de aglomerados populacionais e características socioeconômicas dos grupos populacionais e do meio ambiente (MINISTERIO DA SAUDE, 2005). A transmissão ocorre de pessoa para pessoa, através das vias respiratórias ou por contato direto com as secreções do paciente (SMELTZER e BARE, 2006). É uma doença de notificação compulsória, ou seja, é obrigatória: as autoridades sanitárias têm de ser informadas, por profissionais de saúde da ocorrência de casos ou de surto da doença, visando à adoção de medidas de intervenção pertinentes (BRASIL, 2002).

Sabe-se que as crianças são mais acometidas pela meningite. Isto pode ser explicado por que crianças menores de um ano não apresentam sistema imunológico amadurecido, e também pela forma de transmissão, já que crianças apresentam maior contato físico, seja na escola ou 
até mesmo em casa, durante a recreação, sendo que a faixa etária de maior representatividade é de crianças menores de 9 anos(PAULA, 2003).

A existência de várias etiologias, sobretudo bacterianas e virais, torna o estudo das meningites um tanto complexo (PAULA, 2003). Dentre as várias etiologias de meningite, a bacteriana é a mais severa, apresentando o maior número de casos letais e com maior número de sequelas. De modo geral a meningite bacteriana é predominante no inverno. A ocorrência demeningitebacterianavariamuito entree dentro das regiões, países, estados,e os municípios, tanto em relação às faixas etáriasmais afetadasquantoà freqüênciados agentes etiológicosprevalentes (SOUZA, 2012). Por outro lado, a meningite asséptica, anteriormente denominada viral, é mais frequente na primavera e verão. As meningites assépticas ocorrem em qualquer idade, sendo mais prevalentes nas crianças (LOGAN e MACMAHON, 2008). O principal agente etiológico é o enterovírus, que predomina nos meses quentes. A meningite asséptica causada por este agente etiológico normalmente tem duração menor que uma semana, sendo os lactentes os mais suscetíveis (PERES et al., 2006).

Diante desse cenário, a abordagem desenvolvida neste estudo teve como objetivo avaliar a influência de variáveis climáticas locais sobre a incidência mensal de meningite em crianças, na faixa etária entre 0 e 9 anos ,no Município de Ponta Grossa, Paraná, no período de 2002 a 2011.

\section{MATERIAIS E MÉTODOS}

O clima de Ponta Grossa (localizada geograficamente na Figura 1), segundo a classificação de Köppen, se caracteriza como Cfb, o qual, segundo dados do IAPAR (2000), citado por Cruz (2007) correspondem ao clima temperado propriamente dito com temperatura média no mês mais frio abaixo de $18^{\circ} \mathrm{C}$ e temperatura média no mês mais quente abaixo de $22^{\circ} \mathrm{C}$, sem estação seca definida. A precipitação pluviométrica anual fica em torno de $1200 \mathrm{~mm}$ a 1400 $\mathrm{mm}$ e a umidade relativa anual permanece entre $75 \%$ e $80 \%$ (CRUZ, 2007). As estações do ano são bem definidas: os invernos são frios e os verões, quentes. As chuvas são bem distribuídas ao longo do ano: todos os meses são úmidos (MAACK, 1981).

A presente pesquisa apresenta caráter epidemiológico e descritivo. Dados climatológicos históricos da cidade de Ponta Grossa, abrangendo uma série de 10 anos, foram analisados. Tais dados são provenientes da estação meteorológica de Ponta Grossa pertencente ao Instituto Tecnológico SIMEPAR, cujas coordenadas geográficas são $23^{\circ} 30^{\prime}$ de latitude leste, $51^{\circ} 32^{\prime}$ de longitude oeste e 746 metros de altitude e referem-se ao período de janeiro de 2002 a dezembro de 2011. As variáveis climáticas selecionadas foram: - Temperatura do ar $\left({ }^{\circ} \mathrm{C}\right)$, Precipitação Pluviométrica $(\mathrm{mm})$ e Umidade Relativa do $\operatorname{Ar}(\%)$. 


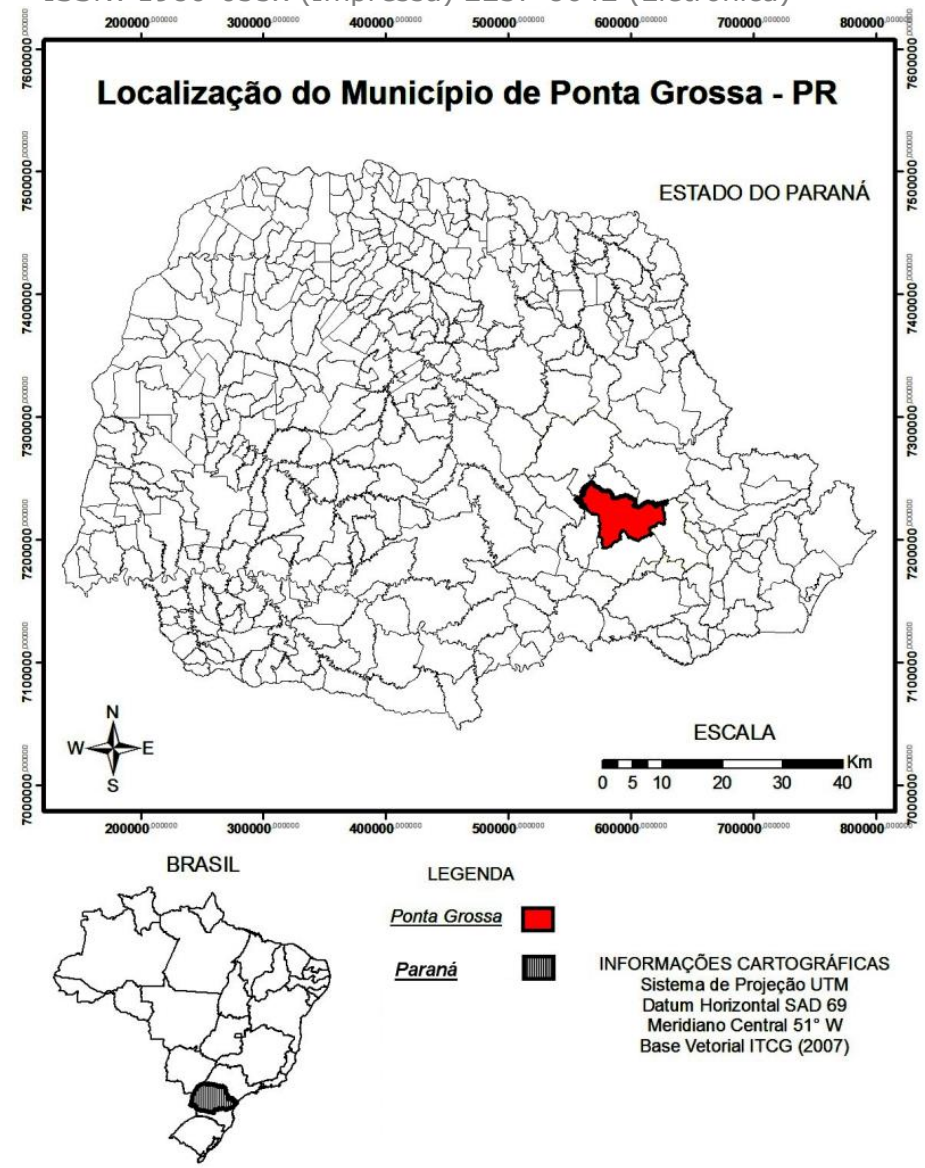

Figura 1- Localização geográfica do município de Ponta Grossa, Paraná, Brasil. Fonte: Adaptado de Neves (2014)

Os dados epidemiológicos referentes à moléstia, relativos ao SINAN (Sistema de Informações de Agravos de Notificação), foram obtidos junto ao Setor da Vigilância Epidemiológica e Controle de Doenças, pertencente à Secretaria Municipal de Saúde da cidade de Ponta Grossa - PR, de acordo com o período de tempo determinado para pesquisa (10 anos). As variáveis selecionadas foram: Idade, Sexo, Tipo de meningite (etiologia) e Evolução do caso.

A amostra inicial foi composta de 592 casos notificados e confirmados de pacientes residentes no município de Ponta Grossa, no período entre 2002 e 2011, tomando como base a data dos primeiros sintomas. A partir da amostra inicial, foram selecionadas 411 fichas, as quais eram correspondentes a crianças na faixa etária entre 0 e 9 anos.

As notificações e investigações dos casos de meningite em crianças foram avaliadas conjuntamente com os dados referentes às variáveis climáticas para a análise de suas possíveis interferências na incidência de meningite. Para isso, empregou-se a técnica de análise de regressão linear simples, conforme modelo teórico (equação 1), com a finalidade de se determinar o maior nível com o qual os elementos climatológicos, avaliados separadamente, foram capazes de evidenciar a relação entre o clima e a incidência da patologia.

$$
y=a x+b
$$

onde "a"é o coeficiente linear, o qual representa o intercepto da reta com o eixo y;"b" é o coeficiente angular, que representa a variação de y em função da variação de uma unidade da variável $x ; " x$ " é a variável independente, no caso as variáveis climáticas e " $y$ " é a variável dependente, o coeficiente de incidência. 
Os cálculos dos coeficientes de incidência mensal para o período em estudo foram expressos por 10.000 habitantes. Para a realização do cálculo, se considerou como população exposta ao risco, projeções baseadas nos censos realizados pelo Instituto Brasileiro de Geografia e Estatística - IBGE, no referido período.

O Coeficiente de Incidência mensal médio (CI) foi dado por:

$$
C I=Y_{t}
$$

Em que $Y_{t}$ é a média aritmética dos coeficientes de incidência calculados para todos os meses equivalentes, no período em estudo.

Para quantificar a letalidade populacional anual, devido à meningite, no período selecionado, o cálculo do coeficiente de letalidade foi utilizado:

$$
\mathrm{CL}=\frac{\text { Númerodeóbitospormeningite }}{\text { Númerototaldecasosdemeningite }} \times 100
$$

A pesquisa foi aprovada, em 04 de abril de 2012, sob o parecer no $18 / 2012$ pelo Comitê de Ética em Pesquisa com Seres Humanos da UEPG. Os dados obtidos serão utilizados para fins exclusivos de pesquisa científica preservando-se a identidade dos sujeitos, de acordo com a Resolução no 196/96 do Conselho Nacional de Saúde.

\section{RESULTADOS E DISCUSSÃO}

Quanto ao número de notificações de casos de meningite confirmados em crianças, com base na data dos primeiros sintomas, foram registrados, a partir do banco de dados do SINAN 411 casos entre 2002 e 2011. O sexo masculino foi predominante em quase todos os anos, com exceção dos anos de 2002 e 2005, nos quais o sexo feminino apresentou um ligeiro aumento, conforme apresentado na Figura 2.

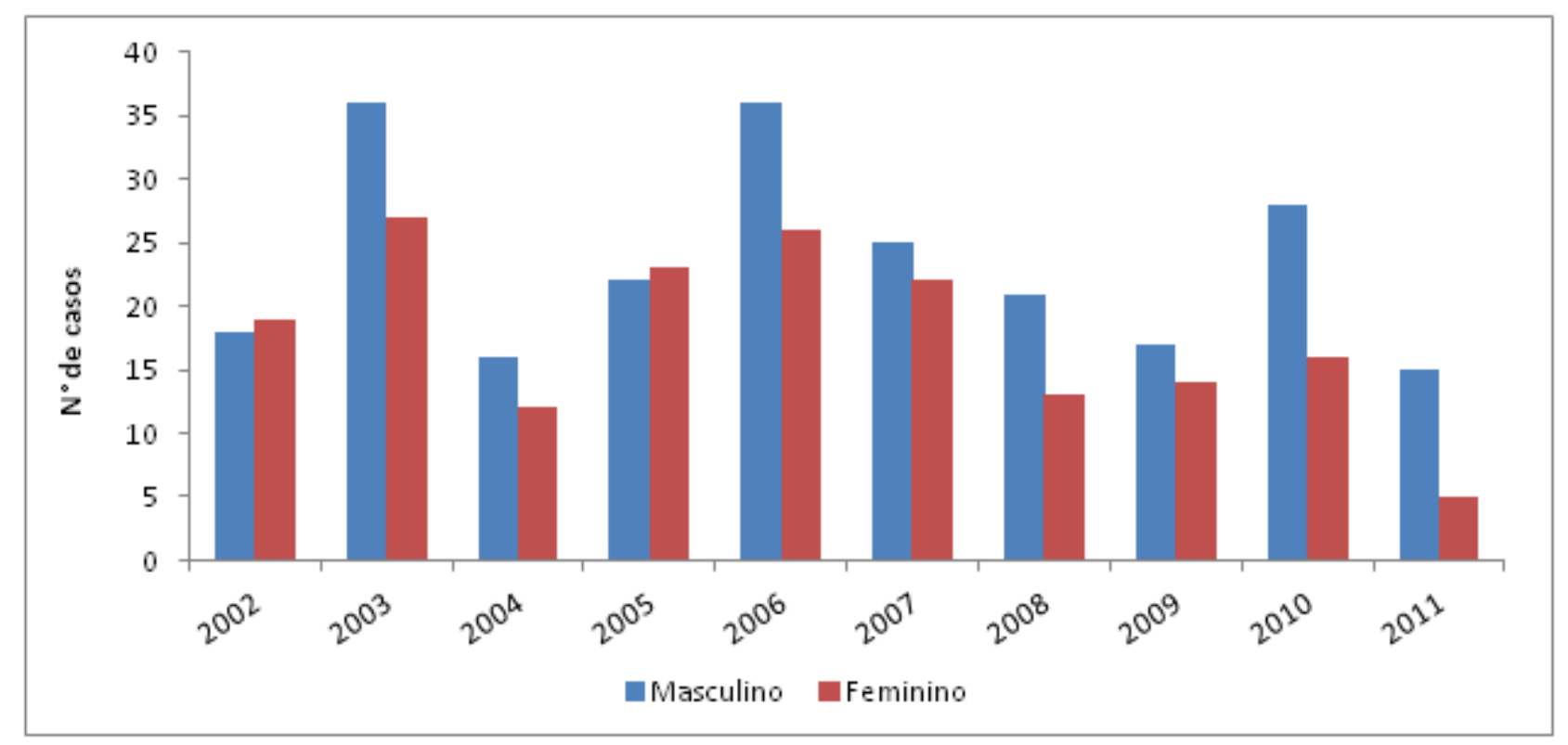

Figura 2- Distribuição de frequência dos casos confirmados de meningite em crianças segundo sexo no município de Ponta Grossa - PR, entre 2002 e 2011. 
A predominância do sexo masculino é coincidente com dados encontrados na literatura, referente a estudos realizados em várias localidades do Brasil, e do mundo, como por exemplo, Rio de Janeiro e São Paulo (ROMANELLI et al., 2002), (MONTARROYOS, 2005).

Diferentemente do presente estudo, uma pesquisa em Porto Alegre desenvolvida entre 1996 e 1999, apresentou 53\% dos casos diagnosticados de meningite em meninas (MIURA e MARTIN, 2001). Dessa maneira, a associação de casos de meningite com o sexo do paciente pode variar, mesmo que em pequena escala, dependendo da localidade, porém com predominância masculina para a maioria dos estudos analisados.

Com relação à distribuição dos casos de meningite em crianças segundo faixa etária, por ano, a Tabela 1, mostra que o maior número de casos se concentra entre 1 e 4 anos (39,66 \% dos casos), seguida de 5 a 9 anos (36,98\% dos casos). A classe que representa pacientes com menos de 1 ano fica em 30 lugar, com $23,36 \%$.

Tabela 1- Distribuição de frequências absolutas e relativas (\%) dos casos confirmados de meningite em crianças segundo faixa etária no município de Ponta Grossa - PR, entre 2002 e 2011.

\begin{tabular}{cccccccccccc} 
& 2002 & 2003 & 2004 & 2005 & 2006 & 2007 & 2008 & 2009 & 2010 & 2011 & Total \\
\hline$<1$ ano & $11(29,73)$ & $9(14,29)$ & $13(48,15)$ & $9(20,00)$ & $9(14,52)$ & $12(23,40)$ & $5(15,15)$ & $11(34,38)$ & $13(29,55)$ & $4(20,00)$ & $96(23,36)$ \\
1.4 anos & $14(37,84)$ & $27(42,86)$ & $10(37,04)$ & $22(48,89)$ & $20(32,26)$ & $18(38,30)$ & $18(30,30)$ & $9(28,13)$ & $17(38,64)$ & $8(40,00)$ & $163(39,66)$ \\
$5-9$ anos & $12(33,43)$ & $27(42,86)$ & $4(14,81)$ & $14(31,11)$ & $33(53,23)$ & $18(38,30)$ & $10(20,83)$ & $12(37,50)$ & $14(31,82)$ & $8(40,00)$ & $152(36,98)$ \\
Total (\%) & $37(100)$ & $63(100)$ & $27(100)$ & $45(100)$ & $62(100)$ & $48(100)$ & $33(100)$ & $32(100)$ & $44(100)$ & $20(100)$ & $411(100)$ \\
\hline
\end{tabular}

Um dos fatores, mais relatados, responsáveis pela maior incidência de meningite em crianças é o fator social. Crianças costumam permanecer em ambientes fechados, e em maior contato, o que facilita a transmissão, pois apenas com um espirro, o vírus ou bactéria é lançado ao ar. Além disso, o SNC (Sistema nervoso central) apresenta certa imaturidade em crianças. Outro fator que influencia na faixa etária e incidência da meningite é o agente etiológico. Alguns tipos de vírus e bactérias são mais frequentes em determinada faixa etária.

Nos recém-nascidos, os estreptococos e os bacilos gram-negativos são os principais causadores da meningite. Na criança até cinco anos, predominam o Haemophilus Influenzae, o pneumococo e o meningococo. (CARVALHANAS et al., 2005).

A meningite meningocócica aparece com maior frequência em países em desenvolvimento do que nos desenvolvidos porque quanto maior o número de pessoas por metro quadrado, maiores as chances de contaminação. É um sério problema de saúde pública, especialmente por causo da alta letalidade e da elevada incidência em faixas etárias menores (NORONHA, 1997). Estudo realizado em São Paulo mostrou que casos de meningococemia apresentaram maior frequência em faixas etárias menores de um ano, porém sua letalidade é alta em todas as idades (MASUDA, 2009)

O pneumococo Streptococus pneumoniae causa meningite na mesma frequência que o meningococo, sendo bastante comum na população idosa e de muita preocupação na infância dada sua alta morbi-mortalidade e graves sequelas. Apesar de ocorrer em qualquer idade, mais de $50 \%$ dos pacientes têm menos de 1 ou mais de 50 anos de idade (BEREZIN, 2002; MILLER e JULBERT, 2002).

A meningite tuberculosa é prevalente nos grupos de alto risco, como imuno comprometidos, imigrantes de áreas endêmicas e pessoas altamente expostas (como membros da família e trabalhadores da saúde). Pode ocorrer em qualquer idade, sendo mais comum em crianças e adultos jovens, com suscetibilidade maior nos menores de cinco anos (DEVINSKY, 2001). 
As meningites virais (atualmente denominadas assépticas) acometem qualquer idade, com frequência máxima na infância, entre 5 e 10 anos e são raras após os 40 anos. As meningites virais são duas vezes mais frequentes nos meninos que nas meninas, preponderância que desaparece com a idade (PELLINI, 2004). O enterovírus predomina nos meses quentes e a doença tem duração menor que uma semana, sendo os lactentes os mais suscetíveis (PERES et al., 2006). Estes vírus têm maior possibilidade de serem disseminados quando as pessoas não lavam as mãos antes das refeições, após a utilização das instalações sanitárias, ou depois de manusear fraldas de crianças ou objetos sujos. Podem também ser transmitidos por contato íntimo, comum entre membros de uma mesma família (SECRETARIA ESTADUAL DE SAÚDE, 2008).

Na Figura 3, observa-se a distribuição de frequência absoluta dos casos confirmados de meningite segundo a etiologia nos meses de Janeiro a Dezembro. Pode-se notar que as etiologias bacteriana e asséptica (anteriormente denominada viral), foram as que apresentaram maior assiduidade.

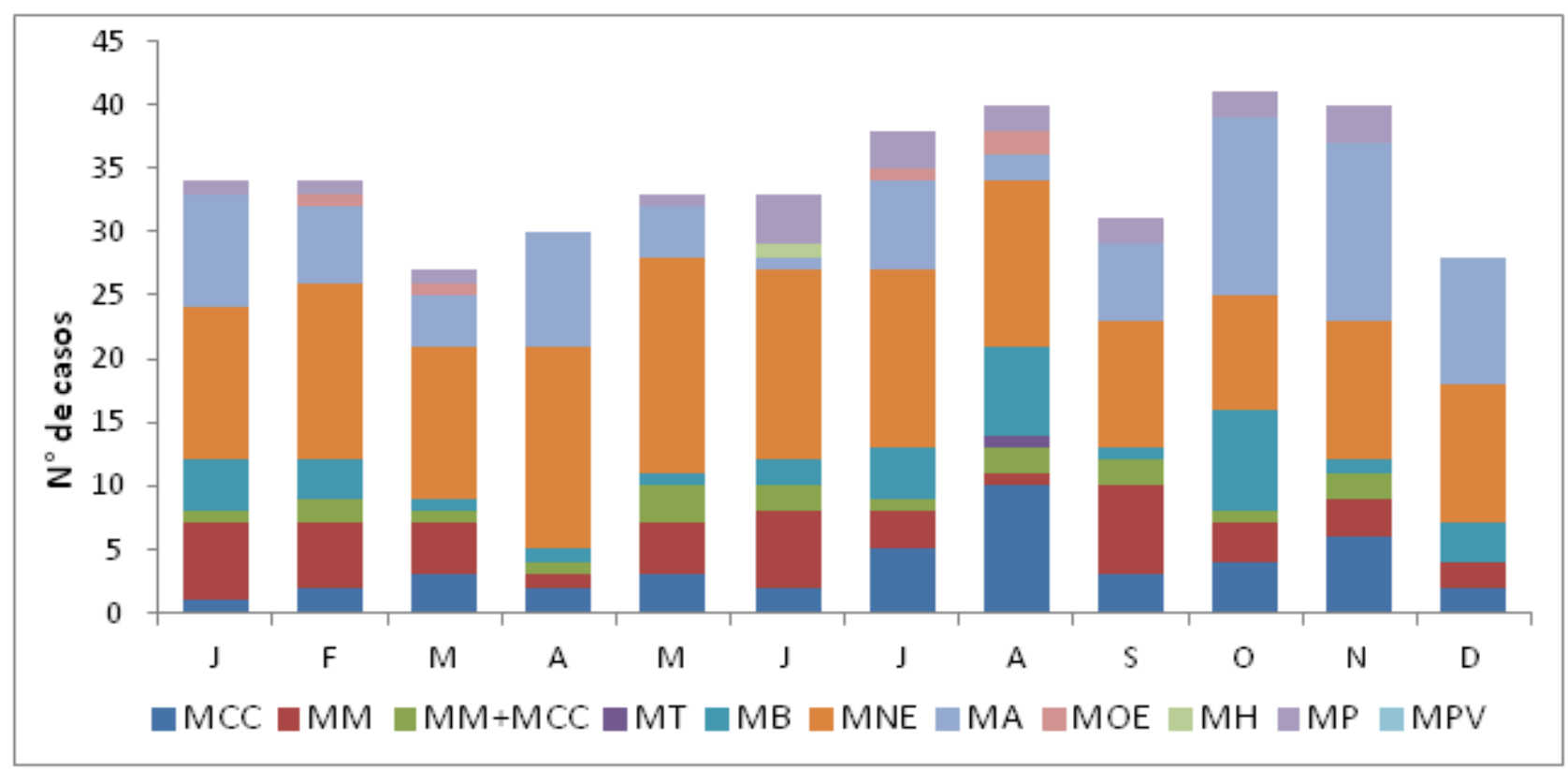

Figura 3 - Distribuição de frequências dos casos confirmados de meningite em crianças segundo etiologia: MCC (Meningococemia), MM (Meningite meningocócica), MM + MCC (Meningite meningocócica com meningococemia), MT (Meningite tuberculosa), MB (Meningite bacteriana), MNE (Meningite não especificada), MA (Meningite asséptica), MOE (Meningite de outra etiologia), MH (Meningite por hemófilos), MP (Meningite por pneumococos) e MPV (Meningite pós-vacinal) no município de Ponta Grossa - PR, nos meses de Janeiro a Dezembro, entre 2002 e 2011.

Como pode ser observado na Figura 3, a etiologia asséptica (MA) é prevalente a partir de Outubro, apresentando nos meses de Outubro a Janeiro os maiores números de casos para o período em estudo, o que é condizente com um estudo realizado no Paraná entre 1992 e 2001, onde a incidência de meningite viral (atualmente denominada asséptica) foi maior nos meses mais quentes do ano (outubro a janeiro) (PAULA,2003). Dessa maneira a etiologia asséptica pode ser considerada sazonal, sendo que sua época de ocorrência mais frequente é a partir do mês de Outubro, começando a diminuir a partir do mês de Março, porém, com presença de casos confirmados em todos os meses do ano. Exceções foram observadas nos meses de Abril e Julho que ainda apresentaram um número considerável de casos. O mês de Junho apresentou o menor número de casos de meningite asséptica para 0 período do estudo.

As meningites bacterianas, que enquadram as Doenças Meningocócicas (MCC, MM e MM + $M C C$ ), meningite tuberculosa (MT), meningite bacteriana não especificada (MB), meningite por hemófilos $(\mathrm{MH})$ e meningite por pneumococos (MP), também podem ser consideradas 
sazonais, uma vez que sua frequência é aumentada a partir de maio, tendo um ápice no mês de agosto, diminuindo a partir de Novembro.

A Meningite Não Especificada (MNE) é a etiologia que apresenta maior assiduidade e que apresenta maior número de casos para o período em estudo. Uma possível explicação para este fato, é que durante o diagnóstico da doença, não seja possível descobrir a etiologia. Ou seja, a meningite é confirmada, mas não se sabe a etiologia. Então este caso é considerado Não especificado.

Na Figura 4 observa-se o número de curas, óbitos e o coeficiente de letalidade da meningite. Nota-se que o ano de 2003 não apresentou o maior coeficiente de letalidade entre os anos estudados, embora tenha apresentado o maior número de casos notificados de meningite. No presente estudo, de uma maneira geral, houve relato de cura, em média, de $88,98 \%$ durante o período avaliado. No entanto, a letalidade mostrou-se bastante variável, apresentando valores desde 5,26\% em 2008 até $20,37 \%$ em 2007, com um valor médio para todo o período de $11,02 \%$. Esses dados corroboram com outro estudo, em Goiânia, que encontrou evolução para cura em $85 \%$ dos casos (VIEIRA,2001). Assim como em uma pesquisa realizada por Labiak et al., 2007 na cidade de Ponta Grossa, referente ao período de 2001 a 2005, um resultado semelhante foi encontrado, onde o percentual médio de cura foi de $88,73 \%$ e o índice médio de letalidade foi de 11,27\%. Em Santa Catarina, a letalidade média foi de 12,6\% entre 2000 a 2004, sendo que em 2002 houve aumento da incidência das meningites virais (SECRETARIA ESTADUAL DE SAÚDE, 2008). No Paraná, no período de 1992 a 2001, o grupo das meningites de maior incidência foi o das meningites assépticas. No entanto, a meningite meningocócica além de apresentar alta incidência, foi a que apresentou maior letalidade anual média com 19,5\% de óbitos (PAULA, 2003).

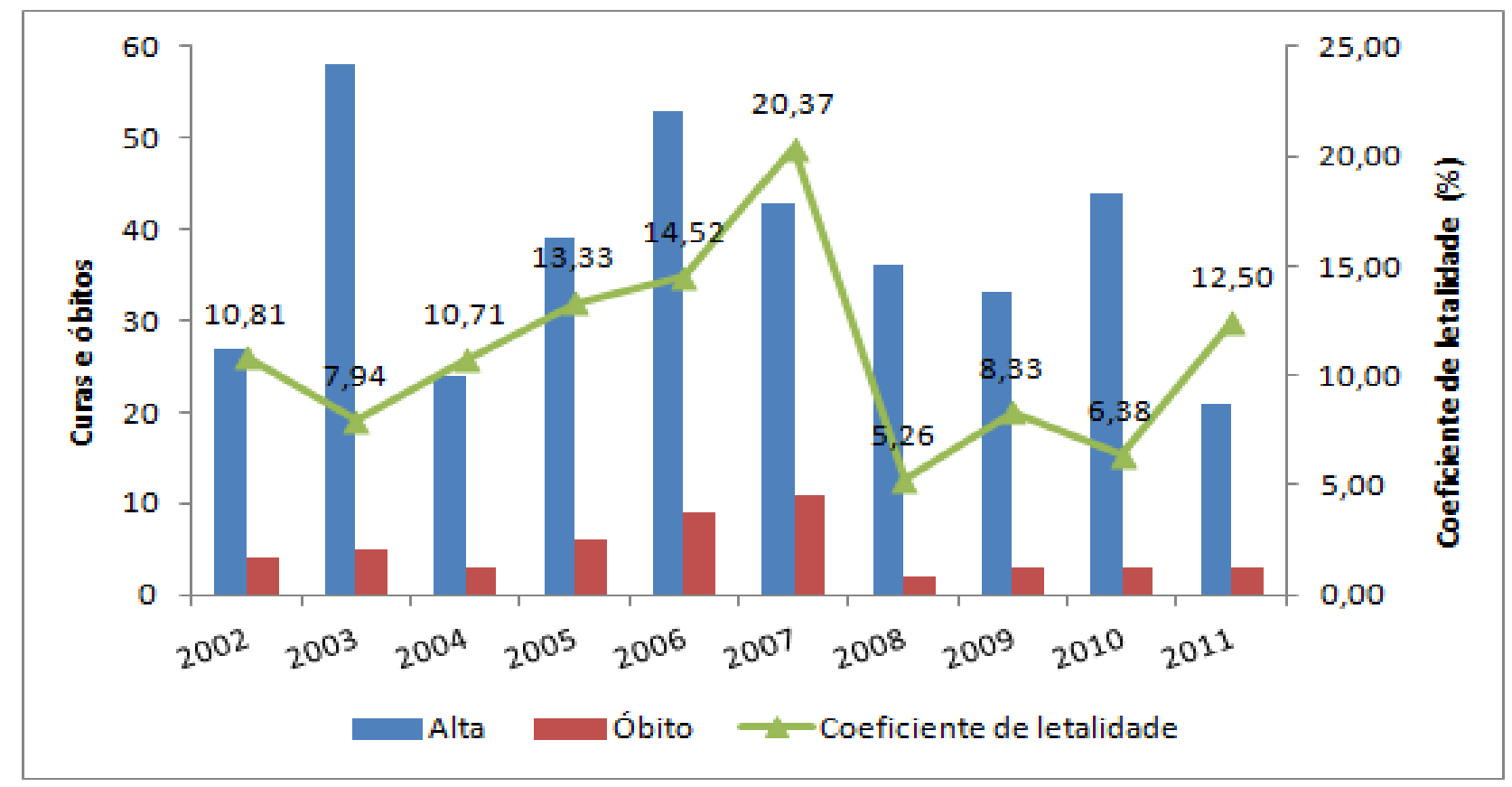

Figura 4 - Casos de meningite em crianças por ano segundo cura, óbitos e taxa de letalidade, no município de Ponta Grossa - PR, entre 2002 e 2011.

É provável que a etiologia da meningite, seja a principal razão da diferença nos coeficientes de letalidade no decorrer dos anos. As meningites que tem uma bactéria como agente patológico são mais agressivas, e consequentemente mais letais. $E$ as meningites que são transmitidas por vírus, apresentam letalidade mais baixa.

Na Figura 5 se pode avaliar os comportamentos dos coeficientes de incidência de meningite em relação às variáveis climáticas separadamente. Na Figura $5 \mathrm{~A}$, o coeficiente de incidência 
aumenta juntamente com a temperatura média do ar. $O R^{2}$ no valor de 0,1278 sugere que esta variável climática isoladamente não consegue explicar de forma satisfatória a incidência de meningite em crianças no Município de Ponta Grossa para o período de estudo. Já na Figura 5B, observa-se um decréscimo do coeficiente de incidência à medida que a quantidade de chuva aumenta. Neste caso, o $\mathrm{R}^{2}$ apresenta um valor de 0,8375 , sugerindo que essa variável climática em particular tem uma maior correlação com o comportamento da referida doença. Na Figura 5C o valor do $\mathrm{R}^{2}$ é de 0,0646 , ou seja, praticamente sem correlação, mas é possível perceber um ligeiro decréscimo do coeficiente de incidência com o aumento da umidade relativa do ar.

A análise da Figura 6 complementa a informação acima onde se pode compreender o comportamento dos coeficientes de meningite, conjuntamente com as variáveis climáticas. 0 que fica claro é que, considerando-se cada variável em particular, existe um período do ano em que a ocorrência da doença está em plena sintonia com as tendências da variável, enquanto em outros a doença parece ocorrer em outro ritmo. Como exemplo, nos meses de Março e Abril, à medida que a temperatura e a precipitação pluviométrica diminuem, há uma diminuição de casos desta enfermidade neste local. Como pode ser observado, Abril e Maio apresentaram as menores incidências médias de meningite, sendo os coeficientes médios em torno de $0,13 / 10.000$ habitantes. No mês de Setembro, o início do aumento da temperatura e a umidade relativa do ar ligeiramente mais baixa possivelmente contribuíram para diminuir de forma sutil a incidência nesse mês.

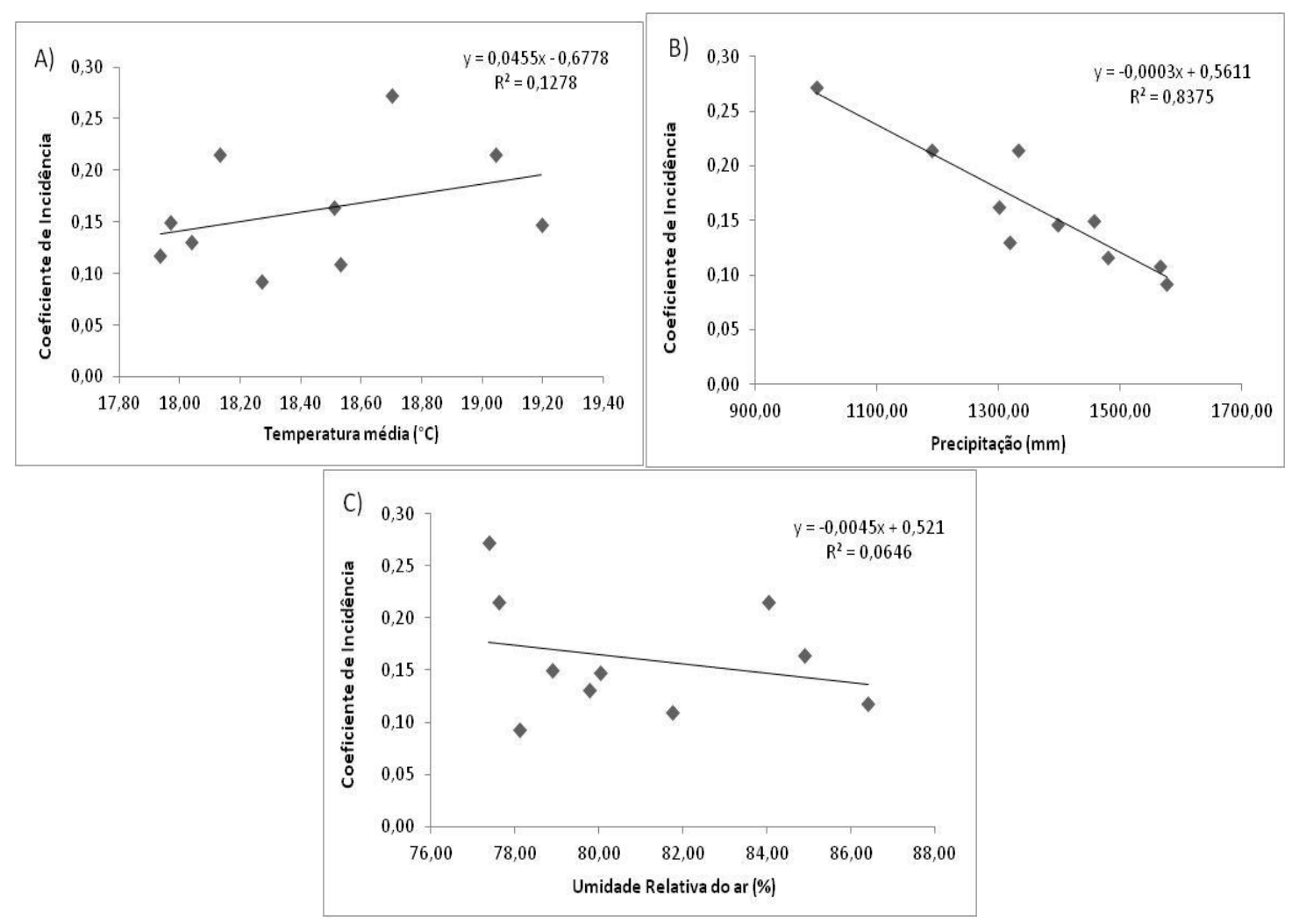

Figura 5 - Tendências dos coeficientes de incidência de meningite em crianças em relação às variáveis climáticas: Temperatura média, Precipitação Pluviométrica e Umidade Relativa do Ar no município de Ponta Grossa - PR, 20022011. 


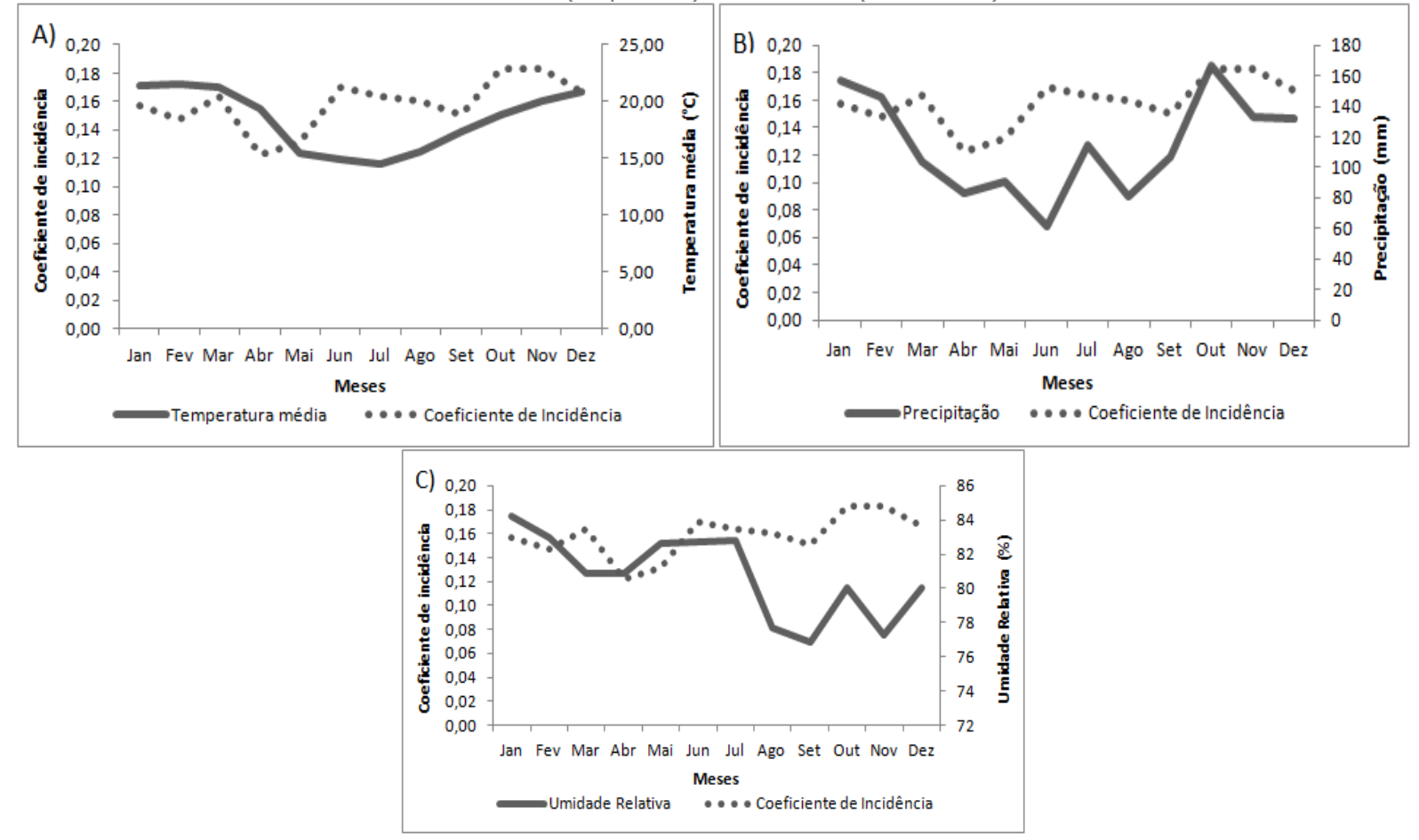

Figura 6 - Variação média mensal da incidência de meningite em crianças, variação mensal da temperatura média do ar $(A)$, totais mensais de precipitação pluviométrica $(B)$ e umidade relativa do ar mensal $(C)$, no município de Ponta Grossa - PR, nos meses de Janeiro a Dezembro, entre 2002-2011.

Observou-se ainda elevada incidência de meningite nos meses de Outubro e Novembro, provavelmente devido aos acréscimos da temperatura do ar e da precipitação pluviométrica. Verificou-se, porém, que nos meses de Outubro e Novembro o percentual de umidade relativa do ar foi ligeiramente inferior, sugerindo que esse elemento climático pode ter sido um dos fatores relacionados com o aumento da incidência observada no período.

No entanto, existem meses em que a análise das variáveis climáticas parece ser insuficiente para explicar a dinâmica desta doença, como em Janeiro e Fevereiro, os quais apresentaram elevadas temperaturas médias, entretanto, não foram os meses com o maior coeficiente de incidência. Assim como Junho, que apresentou um aumento da doença em relação aos meses de Abril e Maio, associado a uma baixa temperatura média para período em estudo.

Após estas observações, parece ficar claro que o comportamento desta doença é complexo e que a época de ocorrência mais frequente desta enfermidade depende não somente das variáveis climáticas, mas também das características do agente etiológico, da suscetibilidade da população, da sua exposição ao agente etiológico, do tipo de meningite, além da classe social dos indivíduos. No entanto, é possível afirmar que as condições climáticas favorecem o contágio da meningite, já que os hábitos da população mudam conforme as épocas do ano.

\section{CONCLUSÃO}

Com relação às notificações de casos de meningite em crianças confirmados no município de Ponta Grossa - PR, os anos com maior número de casos, durante o período avaliado, foram 2003 e 2006. Quanto ao perfil epidemiológico, o gênero masculino predominou em quase todos os anos estudados, e crianças entre 1 e 4 anos, apresentaram um maior número de casos. Quanto à conclusão do caso, o ano de 2007 foi o que apresentou maior coeficiente de letalidade.

Com relação à incidência da doença, percebeu-se que no município de Ponta Grossa os meses que apresentaram maior coeficiente de incidência de meningite foram Março, Junho, Outubro e Novembro. Os meses de Abril e Maio, por outro lado, apresentaram a menor incidência 
média de meningite. Setembro também apresentou um valor mais baixo para o coeficiente de incidência.

Com relação às variáveis climáticas, a análise de regressão linear simples demonstrou que a temperatura média e a umidade relativa do ar isoladamente não são bons preditores para a meningite visto que não apresentaram boa correlação face ao coeficiente de incidência. Por outro lado, a precipitação pluviométrica apresentou uma alta correlação com o coeficiente de incidência, o que permitiu ajustar um modelo linear que estima com boa acurácia este coeficiente, sugerindo que esta variável climática interfere na incidência dos casos de meningite.

Desta forma, pode-se afirmar que o momento de ocorrência mais frequente desta enfermidade depende da combinação entre as variáveis climáticas locais, o agente etiológico, o tipo de meningite, e a classe social do paciente.

\section{AGRADECIMENTOS}

Ao Instituto Tecnológico SIMEPAR pelo fornecimento dos dados climatológicos, a Gerência de Vigilância Epidemiológica e Controle de Doenças pela colaboração no acesso às fichas de notificações e investigações de doenças sobre meningite e à Fundação Araucária pelo suporte financeiro.

\section{REFERÊNCIAS BIBLIOGRÁFICAS}

ARAUJO, R.R.; NUNES, J.S.A. Relações geográficas entre o clima e a incidência de dengue na cidade São Luiz - MA.Ciências Humanas em Revista, São Luiz, v.6, n.2, p. 93-108, dez. 2005.

BEREZIN, E. N. Meningite pneumocócica na infância: características clínicas, sorotipos mais prevalentes e prognóstico. Jornal de Pediatria, Rio de Janeiro, v.78, n.1, p.19-23, 2002.

BRASIL. Ministério da Saúde. Secretaria de Vigilância em Saúde. Guia de Vigilância Epidemiológica. 5. ed. Brasília, v.2, p. 598-630, 2002.

CARVALHANAS, T. R. M. P.; BRANDILEONE, M. C. C.; ZANELLA, R. C. Meningites bacterianas. Boletim Epidemiológico Paulista, ano 2, n. 17, maio 2005. Disponível em: < http://www.cve.saude.sp.gov.br/agencia/bepa17_meni.htm>. Acesso em: 21 out. 2013.

CRUZ. G. C. F. Alguns aspectos do clima dos Campos Gerais. In: MELO, M. S.; MORO, R. S.; GUIMARÃES, G. B. Patrimônio Natural dos Campos Gerais do Paraná. 1. ed. Ponta Grossa: Editora UEPG, 2007, cap. 5. p. 59-72.

DAVIS, L. E. Infecções do Sistema Nervoso Central. In: WEINER, W. J.; GOETZ, C. G. Neurologia para o não-especialista. 4. ed. São Paulo: Santos, 2003, cap. 24, p. 397-401.

DEVINSKY, O. Infecções do SNC. In: Manual do residente em neurologia. Rio de Janeiro: Revinter, 2001, cap. 20, p. 197-209.

IBGE - INSTITUTO BRASILEIRO DE GEOGRAFIA E ESTATÍSTICA. Contagem da população 2007: população residente em $1^{\circ}$ de abril de 2007, segundo os municípios: Paraná. Rio de Janeiro, 2007. Disponível em: <http://www.ibge.gov.br/ home/estatistica/populacao/contagem2007/PR.pdf>. Acesso em: 21 out. 2013.

LABIAK, V.B.; STOCCO. C.; LIMA LEITE, M.; VIRGENS FILHO, J.S. Aspectos epidemiológicos dos casos de meningite notificados no município de Ponta Grossa- PR, 2001 - 2005. Cogitare Enfermagem, Curitiba, v. 12, n. 3, p.306-312, Jul/Set, 2007.

LOGAN SA, MACMAHON E. Viral meningitis. BMJ Research, London, v. 336, n. 7634, p. 36 - 40, 2008

MAACK, R. Geografia física do Estado do Paraná. 2.ed. Rio de Janeiro: J. Olympio, 1981.

MASUDA, E.T. Doença meningocócica: indicadores de gravidade e sua importância para vigilância e assistência médico hospitalar. 2009. 133 f. Dissertação - Faculdade de Saúde Pública da USP, Universidade de São Paulo, São Paulo, 2009.

MEDONÇA, F.A.; SOUZA, A.V.; DUTRA, D.A. Saúde pública, urbanização e dengue no Brasil. Sociedade \& Natureza, v. 21, n. 3, p. 257-269, dez. 2009.

MILLER, J. R.; JUBELT, B. Infecções bacterianas. In: ROWLAND, L. P. Merrit: tratado de neurologia. 10. ed. Rio de Janeiro: Guanabara Koogan, 2002, cap. 21, p. 86-93. 
MINISTÉRIO DE SAÚDE (BR). Secretaria de Vigilância em Saúde. Guia de Vigilância Epidemiológica. Cap. 6 - Doenças. Meningites. Departamento de Vigilância Epidemiológica - Brasília, 2005.

MIURA,E.; MARTIN, M.C. Group B streptococcal neonatal infections in Rio Grande do Sul, Brasil. Revista do Instituto de Medicina Tropical de São Paulo, São Paulo, v.43, n.5, p.243-246, 2001.

MONTARROYOS, U.R. Modelos de séries temporais na obtenção de estimativas em casos da doença meningocócica. Dissertação - Universidade Federal de Pernambuco, Recife, 2005.

MURARA, P.G.; TRINDADE AMORIM, M.C.C. Clima e saúde: variações atmosféricas e óbitos por doenças respiratórias. Revista Brasileira de Climatologia, v. 6, n. 6, p. 79-92, 2010.

NEVES, G.L. Impacto das mudanças climáticas globais na disponibilidade hídrica do solo no município de Ponta Grossa, PR. Trabalho de conclusão de curso de pós-graduação em Gestão Ambiental Universidade Federal do Paraná, Curitiba, 2014.

NORONHA,P.C.; BARAN, M.; NICOLAI, A.C.C.; AZEVEDO, B.M.; BERNARDES, O.T.A.; MONTEIRO, R.T.G. et al. Epidemiologia da doença meningocócica na cidade do Rio de Janeiro: modificações após a vacinação contra os sorogrupos B e C. Caderno de Saúde Pública, v.13, p. 295-303, 1997.

OLIVEIRA, J.S. Variáveis Meteorológicas e as ocorrências de doença meningocócica no município de Manaus de 2007 a 2009. Monografia - Universidade de São Paulo, São Paulo, 2011.

PAULA, E.V. Evolução temporo-espacial das meningites no Estado do Paraná ao longo do século XX: abordagem climatológica. In: SIMPÓSIO BRASILEIRO DE SENSORIAMENTO REMOTO, 6, 2003. Belo Horizonte. Anais... Belo Horizonte: INPE, 2003. p. 1415-1422.

PELLINI, A. C. G.; BRANDÃO DE ASSIS, D.; MADALOSSO, G.; CESAR, M.L.V.S.; BARBOSA, H.A et al. Investigação de surto de meningite viral - município de São Joaquim da Barra (São Paulo), fevereiro a abril de 2004. Boletim Epidemiológico Paulista, ano 1, n. 7, 2004 . Disponível em: <http://www.cve.saude.sp.gov.br/agencia/bepa7_mv.htm>. Acesso em: 21 out. 2013.

PERES, L. V. C.; CARVALhANAS, T.R.M.P; BARBOSA, H.A.; TIMENETSKY, M. C. S. T.; CAMPÉAS, A. E. Meningite viral. Boletim Epidemiológico Paulista, ano 3, n. 30, jun. 2006. Disponível em: <http://www.cve.saude.sp.gov.br/agencia/bepa30_menviral.htm>. Acesso em: 21 out. 2013.

ROMANELLI, R.M.C.; ARAÚJO, C.A.; DIAS, M.W.; BOUCINHAS, F.; CARVALHO, I.R.; MARTINS, N.R.L.et al. Etiologia e evolução das meningites bacterianas em centro de pediatria. Jornal da Pediatria, v. 78, n.6, p. 467-474, Nov/dez, 2002.

SECRETARIA ESTADUAL DE SAÚDE-PR. Plano Estadual de Saúde. Curitiba, 2012-2015. Disponível em: http://www.sesa.pr.gov.br/arquivos/File/Plano_Saude_2008_2011PR_Final.pdf Acesso em: Jul. 2013.

SMELTZER, S.C.; BARE, B.G. Tradução de Brunner e Suddarth. Tratado de enfermagem médicocirúrgica. 10a ed. Rio de Janeiro: Guanabara Koogan, 2006.

SOUZA, M.O. Estudo do perfil dos exames de líquor, com diagnóstico de meningite, em um Hospital de referência de Salvador. Monografia - Universidade Federal da Bahia, Salvador, 2012.

VIEIRA, J.F.S. Incidência de meningite em pacientes de 0-12 anos no Instituto de Medicina Tropical de Manaus. Arquivos de Neuro-psiquiatria, v.59, n.2, p.227-229, 2001. 